\title{
ERRATUM
}

\section{Effects of candesartan and amlodipine on cardiovascular events in hypertensive patients with chronic kidney disease: subanalysis of the CASE-J study}

Takao Saruta, Koichi Hayashi, Toshio Ogihara, Kazuwa Nakao, Tsuguya Fukui and Kohshiro Fukiyama, for the CASE-J Study Group

Hypertension Research (2009) 32, 1157; doi:10.1038/hr.2009.181

Correction to: Hypertension Research (2009) 32, 505-512; doi: 10.1038/ hr.2009.44

During typesetting and correction of the above paper, Stage 3 was applied twice in Table 3 and published as such. The publishers apologize for this and are now happy to correct this mistake. The correct table is shown below:

Table 3 Comparison of composite cardiovascular end point and each cardiovascular event in various CKD stages

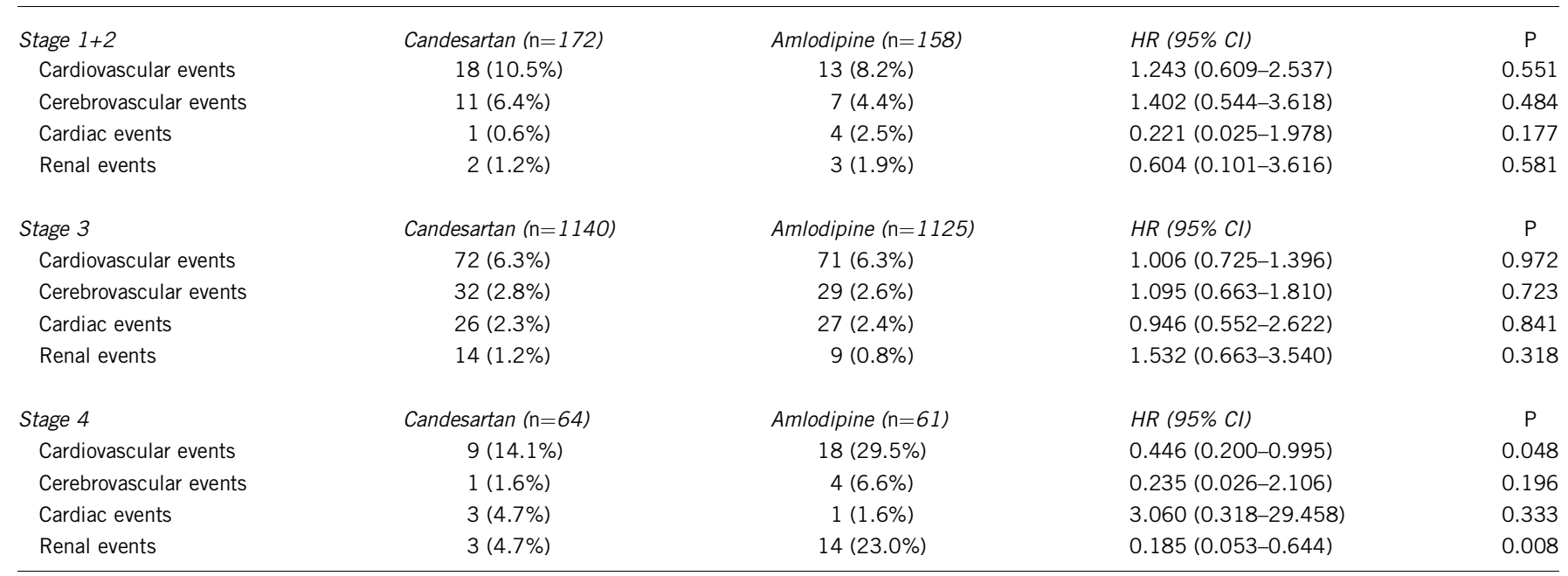

